\title{
Magnetically suspended flywheel in gimbal mount - Test bench design and experimental validation
}

\section{Dagnaes-Hansen, Nikolaj A.; Santos, IImar F.}

Published in:

Journal of Sound and Vibration

Link to article, DOI:

10.1016/j.jsv.2019.01.023

Publication date:

2019

Document Version

Peer reviewed version

Link back to DTU Orbit

Citation (APA):

Dagnaes-Hansen, N. A., \& Santos, I. F. (2019). Magnetically suspended flywheel in gimbal mount - Test bench design and experimental validation. Journal of Sound and Vibration, 448, 197-210.

https://doi.org/10.1016/j.jsv.2019.01.023

\section{General rights}

Copyright and moral rights for the publications made accessible in the public portal are retained by the authors and/or other copyright owners and it is a condition of accessing publications that users recognise and abide by the legal requirements associated with these rights.

- Users may download and print one copy of any publication from the public portal for the purpose of private study or research.

- You may not further distribute the material or use it for any profit-making activity or commercial gain

- You may freely distribute the URL identifying the publication in the public portal

If you believe that this document breaches copyright please contact us providing details, and we will remove access to the work immediately and investigate your claim. 


\title{
Magnetically Suspended Flywheel in Gimbal Mount - Test Bench Design and Experimental Validation
}

\author{
Nikolaj A. Dagnaes-Hansen, Ilmar F. Santos* \\ Department of Solid Mechanics, Technical University of Denmark, Kgs. Lyngby, Denmark
}

\begin{abstract}
This article deals with the design of a test bench and its dynamic testing. The test bench is composed of a rotor levitated by radial active magnetic bearings and axially by a permanent magnet bearing. The rotor housing is mounted in a passive gimbal and the foundation can translate and rotate to emulate a vehicle accelerating, manoeuvring, and subject to outer perturbations such as waves. The work is motivated by a lack of publically available experimental designs and experimental data for magnetically suspended flywheels on moving foundations. The article will describe the test rig design and subcomponents, present experimental results, and afterwards the test rig will be used to experimentally validate a mathematical model governing the dynamics of the system. It is found that the model successfully captures the dynamics of rotor and housing both in a gimballed and non-gimballed flywheel energy storage system when subject to accelerations of the foundation. The simulated maximum housing accelerations are found to deviate 2 $\%$ from the experiments while the maximum rotor displacements are found to deviate $37 \%$, but only for rotor displacements larger than $100 \mu \mathrm{m}$ where the linear approximation to the magnetic forces is no longer accurate.
\end{abstract}

Keywords: Flywheel Energy Storage; Magnetic Bearings; Multi-body dynamics; Electromagnetism;

Rotordynamics; Multiphysics.

\section{Introduction}

The design of magnetically suspended flywheel energy storage systems (FESS) for vehicle applications is problematic due to movements and outer perturbations which significantly affect system performance. To improve the design, both mathematical modelling and experimental testing are needed. A FESS installed on-board a vehicle is experimentally tested in [1] [2] [3] [4] [5. It is important to highlight that in all of these cases, the authors decide to mount the FESS in a gimbal mount. The original contribution of each of these references consists of different experimental tests (a thorough account of the original contributions

\footnotetext{
*Corresponding author. Tel.: +45 256269

Email address: ifs@mek.dtu.dk (Ilmar F. Santos)
} 


$\begin{array}{ll}\text { Abbreviation } & \text { Meaning } \\ \text { AMB } & \text { Active Magnetic Bearing } \\ \text { CAD } & \text { Computer-Aided Drawing } \\ \text { FESS } & \text { Flywheel Energy Storage System } \\ \text { FPGA } & \text { Field-Programmable Gate Array } \\ \text { FRF } & \text { Frequency Response Function } \\ \text { PMB } & \text { Permanent Magnet Bearing } \\ \text { PWM } & \text { Pulse-Width Modulation } \\ \text { RPM } & \text { Rounds Per Minute }\end{array}$

\section{Symbol Meaning}

Units

$\alpha$

First gimbal rotation

$\mathrm{rad}$

$\beta \quad$ Second gimbal rotation

$\mathrm{rad}$

$\Delta \quad$ Radial displacement of rotor

$\delta$

$\frac{\pi}{2}$-latitude of vehicle with FESS

$\mathrm{rad}$

First rotor tilt angle

$\operatorname{rad}$

Second rotor tilt angle

$\mathrm{rad}$

Vehicle pitch angle

$\mathrm{rad}$

$\mu_{0}$

Permeability in vacuum

$\mathrm{H} / \mathrm{m}$

Friction coefficient of bearing

$\mathrm{m}^{2} \mathrm{~N} / \mathrm{s}$

Friction coefficient of bearing

Torque

$\mathrm{Nm}$

Vehicle roll angle

$\operatorname{rad}$

Vehicle yaw angle

$\mathrm{rad}$

$\Omega \quad$ Rotational speed

$\mathrm{rad} / \mathrm{s}$

A

Cross-sectional area

$\mathrm{m}^{2}$

a Length from rotor CM to AMB A

$\mathrm{m}$

$B_{i} \quad$ Body attached frame number $i$

$b \quad$ Length from rotor CM to AMB B

$\mathrm{m}$

$c \quad$ Length from rotor $\mathrm{CM}$ to sensor $\mathrm{A}$

$\mathrm{m}$

d Length from rotor CM to sensor B

$\mathrm{m}$

$e \quad$ Length from rotor CM to PMB m

G Gimbal outer diameter 


\section{Symbol Meaning}

$g \quad$ Acceleration of gravity

$h \quad$ Gimbal inner diameter

$h_{0} \quad$ PMB air gap

I Inertial frame

$I_{g_{p}} \quad$ Polar moment of inertia of gimbal

$I_{g_{t}} \quad$ Transversal moment of inertia of gimbal

$I_{h_{p}} \quad$ Polar moment of inertia of housing

$I_{h_{t}} \quad$ Transversal moment of inertia of housing

$I_{r_{p}} \quad$ Polar moment of inertia of rotor

$I_{r_{t}} \quad$ Transversal moment of inertia of rotor

$K_{C} \quad$ Amplifier Gain

$K_{i} \quad$ Integral Gain

$k_{i} \quad$ Force-current factor

$K_{p} \quad$ Proportional Gain

$k_{r} \quad$ PMB radial force-displacement factor

$k_{s} \quad$ Force-displacement factor

$k_{u} \quad$ Motion induced voltage coefficient

$k_{z} \quad$ PMB axial force-displacement factor

L Inductance

$l_{\text {acc }} \quad$ Length, pivot point to accelerometer

M Magnetic Moment

$m$

$n$

$n_{r}$

$n_{z}$

$n_{z}$

$p$

$r$

$T_{d}$

$u$

$x_{0}$

$z_{0}$

\section{Mass}

Number of coil windings

Number of current conductors radially

Number of current conductors axially

Coefficient for friction model

Radius

Derivative time gain

Unbalance amplitude

Nominal AMB air gap

Nominal distance rotor to housing CM

\section{Units}

$\mathrm{m} / \mathrm{s}^{2}$

$\mathrm{m}$

$\mathrm{m}$

$\mathrm{kg} \mathrm{m} \mathrm{m}^{2}$

$\mathrm{kg} \mathrm{m}{ }^{2}$

$\mathrm{kg} \mathrm{m} \mathrm{m}^{2}$

$\mathrm{kg} \mathrm{m}{ }^{2}$

$\mathrm{kg} \mathrm{m}{ }^{2}$

$\mathrm{kg} \mathrm{m}^{2}$

V/A

$1 / \mathrm{s}$

$\mathrm{N} / \mathrm{A}$

$\mathrm{A} / \mathrm{m}$

$\mathrm{N} / \mathrm{m}$

$\mathrm{N} / \mathrm{m}$

$\mathrm{V} /(\mathrm{m} / \mathrm{s})$

$\mathrm{N} / \mathrm{m}$

$\mathrm{H}$

m

$\mathrm{A} / \mathrm{m}$

$\mathrm{kg}$
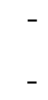

-

m

S

$\mathrm{g} \cdot \mathrm{mm}$

m

$\mathrm{m}$ 
is found in [6]). They focus on experiments and do not address the mathematical modelling of the FESS. Therefore, a mathematical model is needed. This motivates the work carried out in [ $[\underline{6}$ where the derivation and application of a mathematical model governing the motions and forces of a rotor, housing, and gimbalmount on a moving foundation are carried out. The model uses a multi-physical approach in a Newton-Euler framework where motions of rotor, housing and gimbal can be directly extracted along with reaction forces in the system. The motions can be used to investigate stability and the forces can be used to optimise system design. The model is however based on numerous assumptions and simplifications which motivates the need for experimental validation. This work deals with an experimental set-up of the system modelled in $[6]$.

Original contribution of this work

In this context the original contribution of this work is to:

- Provide insight into the design of a modular test rig which can be used to test different designs of all different components of a FESS on a moving foundation.

- Make available experimental data sets with both input accelerations and output movements. These sets can be used by others for benchmarking mathematical models and to assess linear and non-linear dynamical behaviours of subsystems and the entire system.

- Compare experimental and theoretical results in order to shed light on the validity of the model from [6] and discuss relevant improvements.

In section 2 , the experimental test set-up will be described while theory and experiment will be compared in section 3 It should be noted that the experimental test rig will in its current state, not be configured to store or release energy as this is not relevant for the validity of the model.

\section{Test Rig Design}

The test rig can be seen in Figs. 1, 2, and 3. It consists of a rotor fully levitated by magnetic bearings and enclosed by a housing (3). The housing is mounted in a gimbal (2). The gimbal is installed in two frames. One can rotate respectively tilting (1) the other can translate (11). Two pneumatic actuators (8) (9) are used for the rotational and translational movements. The housing and gimbal can also be latched to the tilting frame such that the housing is moving together with the tilting frame, simulating an offshore flywheel.

\section{2.1. Housing and Rotor}

The housing (3) and rotor can be seen in Fig. 3. The rotor consists of an inner steel shaft (24) with the axial permanent magnet bearing (PMB) 28 bolted onto one end and a compressor wheel (19) bolted onto the 


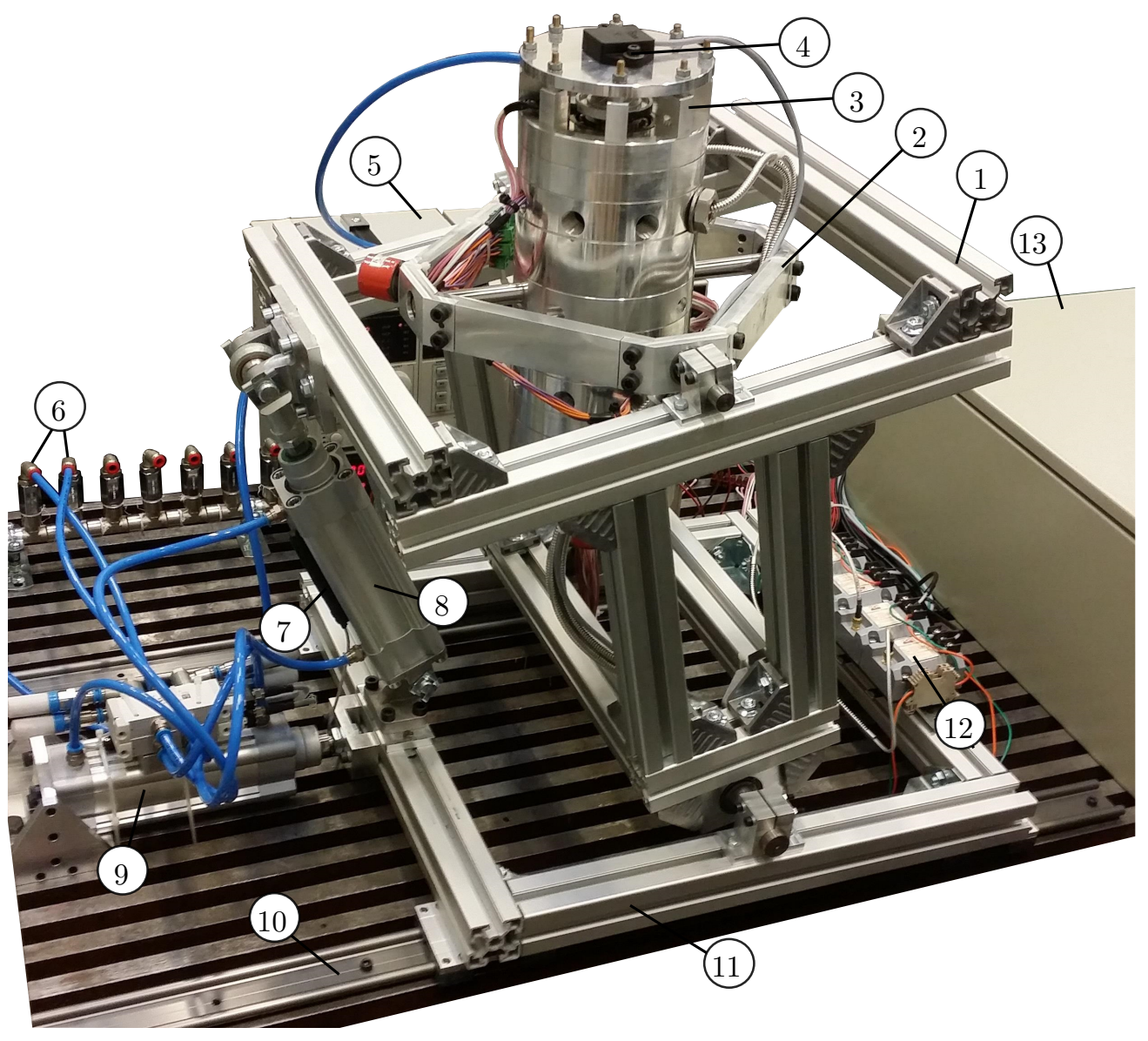

Figure 1: Mechanical Components. (1) Tilting frame, (2) Gimbal, (3) Housing, (4) Accelerometer, (5) Power Supplies for AMBs, (6) Pneumatic Supplies, (7) Pneumatic Actuator Position Sensor, (8) Pneumatic Actuator for Pitching, (9) Pneumatic Actuator for Surging, (10) Rail, (11) Translating Frame, (12) Proximity Probe Conditioners, 13 Electronic Cabinet.

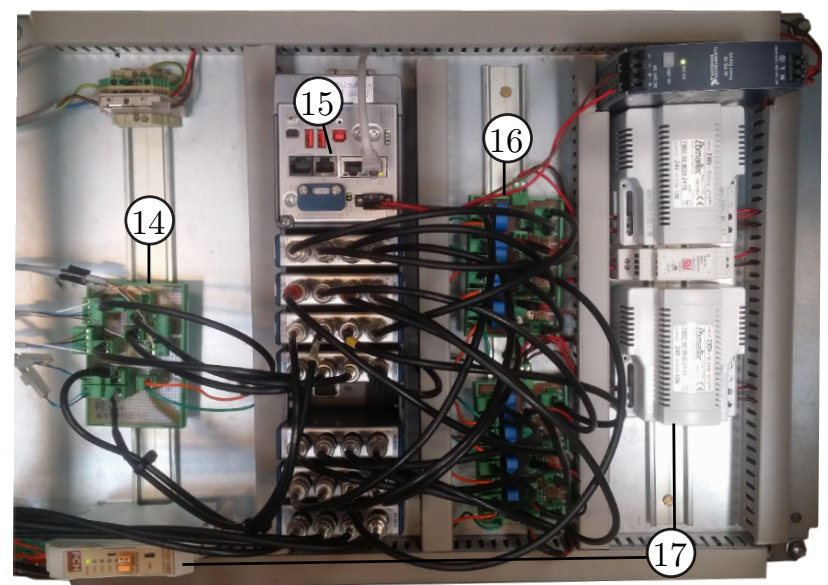

Figure 2: Electronic Cabinet. (14) Conditioning for Accelerometer and Pneumatic Actuator Position Sensor, (15) Digital Processing Unit, (16) H-bridges and Current Sensors, 17 Power Supplies. 
(a)

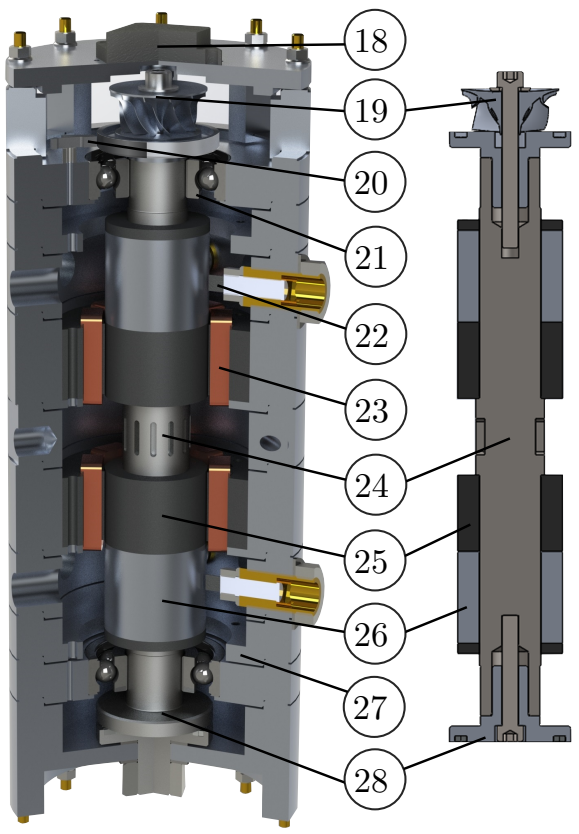

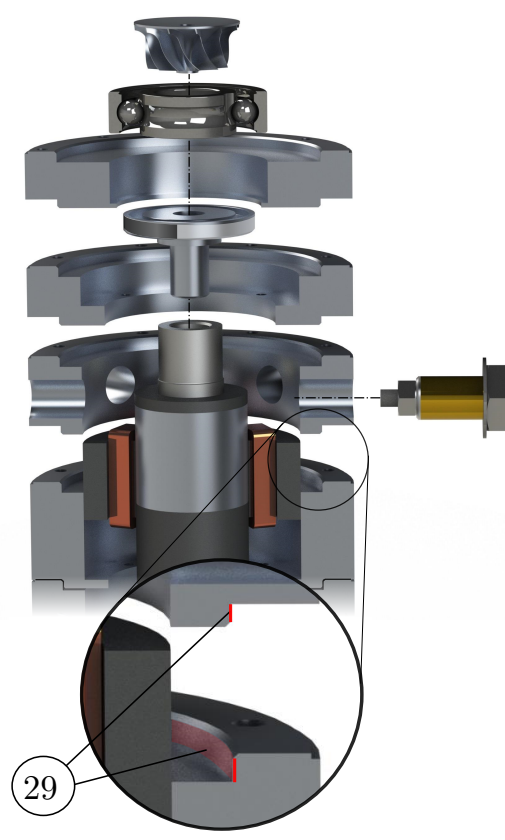

(b)

Figure 3: Flywheel housing and flywheel rotor. (a): Cross-sectional view. (18) Accelerometer, (19) Compressor Wheel, (20) Reflective Infra-red Sensor, (21) Backup Bearing, 22 Proximity Probe, 23 AMB Actuator, (24) Steel Shaft, (25) Magnetic Steel Sheets, (26) Aluminium Hub, 27 Mount for additional proximity sensor, 28 Permanent Magnet Bearing. (b): Exploded view. (29) Guide surfaces.

other end. The sole purpose of the compressor wheel is to spin up the rotor by blowing air onto the wheel. Aluminium hubs (26) are press-fitted onto the steel shaft. The purpose of the hubs is to provide a reliable sensing target for the proximity probes (22). Due to the non-magnetic properties of aluminium, the proximity probes are relieved from experiencing any magnetic run-out [7]. Hubs made of magnetic steel sheets (25) are also press-fitted onto the steel shaft. The first flexible free-free rotor modal frequency has been measured to $1235 \mathrm{~Hz}$.

The housing consists of easy replaceable aluminium modules. Each module serves both as a mount for a component such as a bearing and as a guide pin to accurately align all modules. This modular design allows for changeable machine elements without missing tolerances as illustrated in Fig. 3. Bearings, sensors, etc. can easily be replaced to test different design configurations. For example, the backup ball bearings can readily be replaced with novel backup bearings such as pinned bearings as described in [8] 9]. A currently unused mount 27 for additional disc type proximity sensors as described in [10] can also be seen in Fig. 3 . The highlighted facing surfaces (29) in Fig. 30 are produced with tight tolerances and function as a guide pin for coaxially aligning the modules. The backup bearings (21) are conventional steel ball bearings. The radial air gap between rotor and inner backup bearing racing is $0.2 \mathrm{~mm}$. The proximity sensors (22) are customized eddy-current sensors from PCH Engineering with tip diameter Ø8. They are calibrated for the 

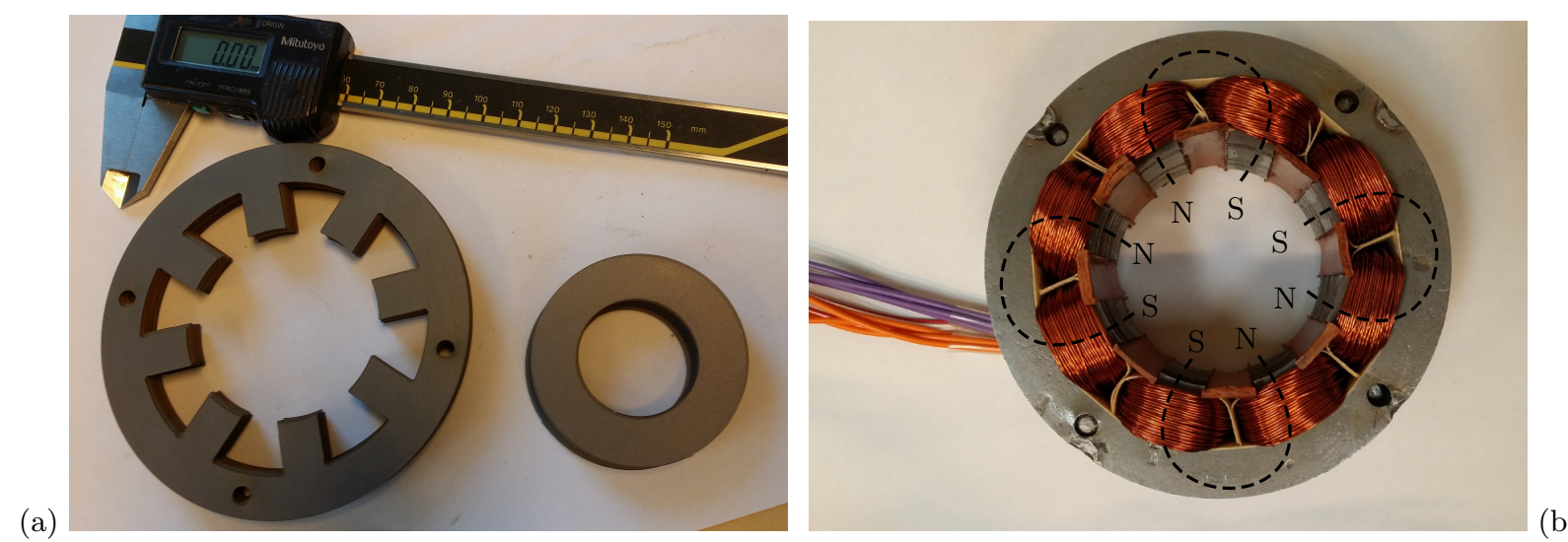

Figure 4: (a): AMB actuator steel sheets of stator and rotor and (b): final stator with coils. $\mathrm{N}$ and $\mathrm{S}$ indicate electromagnetic North and South pole pairs. Each pair make up a one-directional actuator with flux path illustrated as a discontinuous line.

target aluminium (AW2011) with a range of $2 \mathrm{~mm}$, and a sensitivity of $8 \mathrm{~V} / \mathrm{mm}$. A reflective infra-red sensor OPB 704 (20) is mounted on the housing. It is used to determine rotor speed by measuring on a black and white band which is taped onto the rotor. A triaxial accelerometer TE Connectivity 4030-002-120 18 is mounted on top of the housing. The accelerometer has a range of $\pm 2 \mathrm{~g}$ and a sensitivity of $1000 \mathrm{mV} / \mathrm{g}$. This accelerometer is chosen to best fit the expected range of the accelerations.

\subsubsection{Active Magnetic Bearing (AMB) Actuators}

The electrical magnetic steel sheet hubs (25) and the stator cores ${ }^{23}$ consist of $0.35 \mathrm{~mm}$ thick non-oriented grain electrical steel sheets SURA M270-35A [11] with electrical insulation coating (see Fig. [4a) to minimise eddy-currents. However the rotor is, in this heteropolar setup, experiencing larger flux changes and thus larger eddy-currents than the stator and thus one could have used thicker steel sheets for the stator without any considerable increase in eddy-current losses. The radial air gap between the rotor and stator-part of the AMB is $0.45 \mathrm{~mm}$. The stator coils on the stator legs is made of $0.6 \mathrm{~mm}$ copper thread with 175 windings on each leg. The winding configuration of the legs are north-south-south-north-north-south-south-north as seen in Fig. 4 4 b. The rotor hub and the stator have a stacking height of $37.8 \mathrm{~mm}$ and $36.8 \mathrm{~mm}$ respectively. Each stator leg is $10.9 \mathrm{~mm}$ wide. The stator and the rotor core sizes have been chosen together with the number of coil windings $n$ and the maximum coil current to meet to limitations from ohmic heat dissipation in the coil and from flux saturation of the cores.

\subsubsection{Permanent Magnet Bearing (PMB)}

The PMB can be seen in Fig. 5. Each part is made of magnetic steel in which a groove is cut. Arrays of NdFeb $3 \mathrm{~mm}$ cube magnets are glued into the groove. The magnets have magnetization grade N45. They are configured in an outer and inner ring where the outer ring has magnetic north pole facing outwards and 


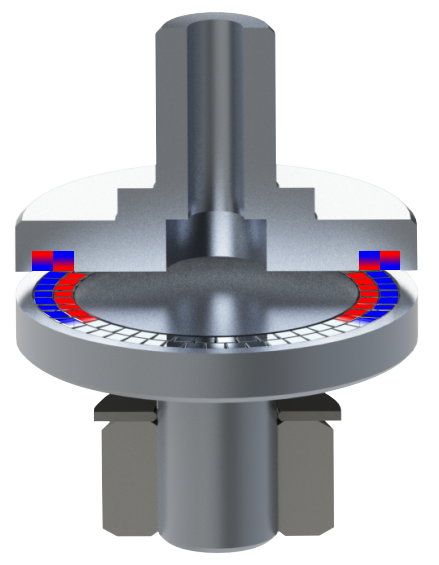

Figure 5: Stator part and cross-sectional view of rotor part of permanent magnet bearing. Red color means magnetic north-pole and blue color means magnetic south-pole.

the inner ring has magnetic south pole facing outwards. The inner and outer radius of the groove is $21.2 \mathrm{~mm}$ and $27.4 \mathrm{~mm}$ respectively.

\subsection{Electronics and Control}

The electronics can be seen in Fig. 2 Each AMB coil current is adjusted using an H-bridge Maxim MAX14879 on a Polulu breakout board (16). The current is measured using transducer LTS 6-NP configured to a range of $\pm 2 \mathrm{~A}$ (16). The digital processing unit (15) is a National Instruments Compact Rio cRIO-9039 with the following modules: Three NI 9402 digital in/out modules for pulse-width modulated (PWM) signals sent to H-bridges and for controlling pneumatic cylinder valves; one NI 9229 analogue input module for measuring accelerometer signals, pneumatic cylinder positions, and infra-red measurement signals; and finally, three NI 9223 modules for measuring position and current. The Compact Rio consists of a real-time processor and a field-programmable gate array (FPGA). The FPGA is used for all digital signal processing such as digital filtering, calibration of input signals, feedback control, and generation of $20 \mathrm{kHz}$ PWM signals. The real-time processor is used for logging and user interfacing. The position feedback control and the current feedback control loops are synchronised and have a frequency of $20 \mathrm{kHz}$. A second-order digital low-pass Butterworth filter with a cut-off frequency of $2500 \mathrm{~Hz}$ is imposed on the position sensor signal. This is necessary for stable levitation due to the noise coming from the sensors. Power supplies (14) for the different components can be seen on the top of the electronics cabinet. In addition, eight adjustable TENMA bench power supplies (5) can be seen at the back of Fig. 1. The TENMA power supplies are used to supply each coil of the AMB individually avoiding coil dynamics of one coil affecting the others. 


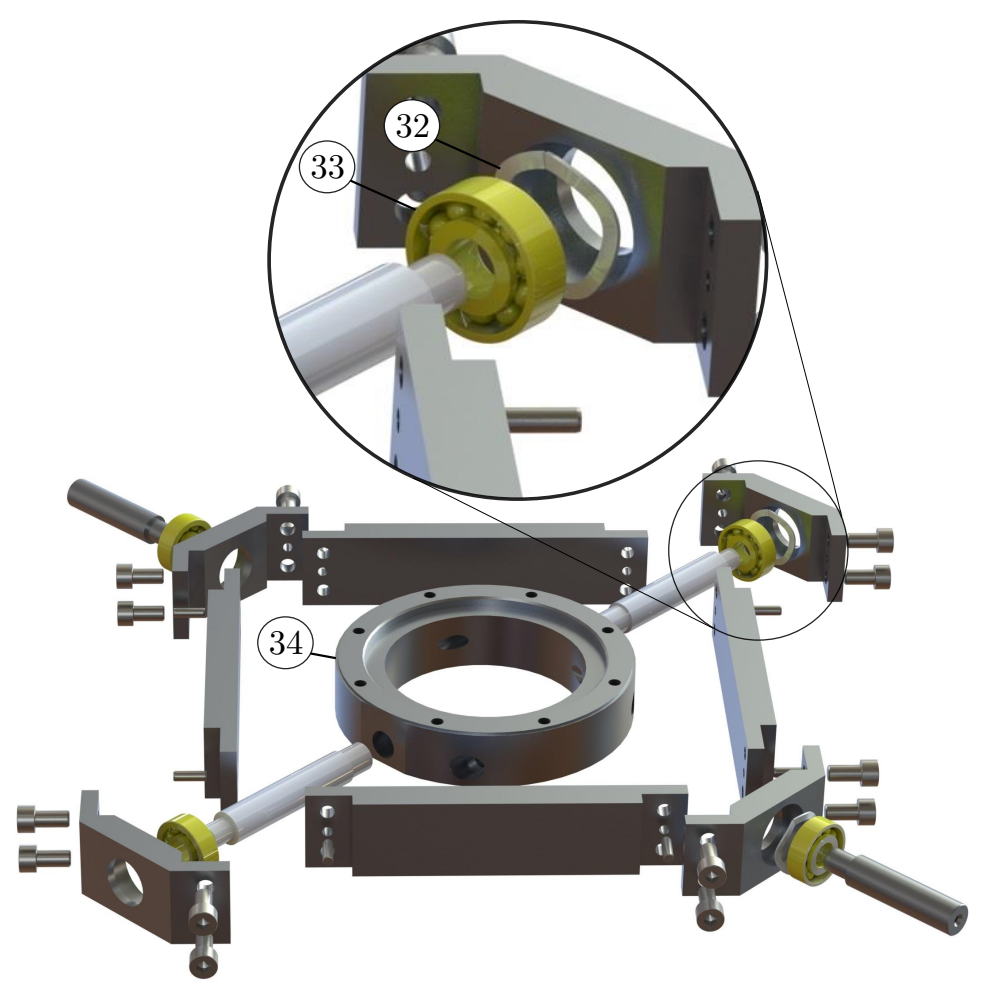

Figure 6: Gimbal ring in exploded view. (32) wave spring, (33) tapered roller bearing, (34) housing module.

\subsection{Gimbal and Moving Foundation} height $40 \mathrm{~mm}$. The tilting frame (1) and translating frame (11) are made of extruded aluminium profiles Bosch Rexroth 45x45L. All rotation joints are made with tapered roller bearings (33) and wave springs (32) as seen in Fig. 6. In this way, any slip in the bearings is minimised. The pneumatic cylinders Festo DSBC50-100-PPSA-N3 (8) (9) have bore diameter $\varnothing 50 \mathrm{~mm}$ and stroke length $100 \mathrm{~mm}$. The pistons are supplied with approximately 12 bar pressure through a directional control valve VUVG-L18-M52-RT-G14-1R8L. The speed of the pistons can be adjusted with mounted throttle valves GRLA-1/4-QS-8-D. The piston position is measured with Festo position transmitter SDAT-MHS-M100-1L-SA-E (7). The translating frame is mounted on Igus DryLin WS 10-40-1000 double rails (10.

\section{Comparison of Theoretical and Experimental Results}

In the following, the mathematical model from [6] is compared to results obtained using the test rig. Several tests have been carried out to investigate the dynamic behaviour of all sub-systems. The tests can be categorized as follows: 
- Stationary housing and foundation (Sec. 3.1): First, the housing is latched to the frame and both frame and housing are not moving. The rotor is perturbed and the resulting rotor-bearing dynamics are investigated.

- Gimballed housing (Sec. 3.2): The housing is now set free to move around in the gimbal mount. The housing is perturbed and the movements of rotor, housing and gimbal are investigated. The foundation is still not moving.

- Moving foundation (Sec. 3.3): The foundation is moving by tilting and translating the frames. The resulting dynamics of gimbal, housing, and rotor are investigated both when the housing is gimballed and not gimballed.

\subsection{Dynamics of Rotor and Magnetic Bearings}

The rotor-bearing dynamics are investigated by perturbing the levitated rotor using the active magnetic bearings. The rotor is not rotating. The AMB's are operated in differential, decentralised mode. In Fig. 7 and 8 the rotor displacements at the location of the sensors are shown. The perturbation consist

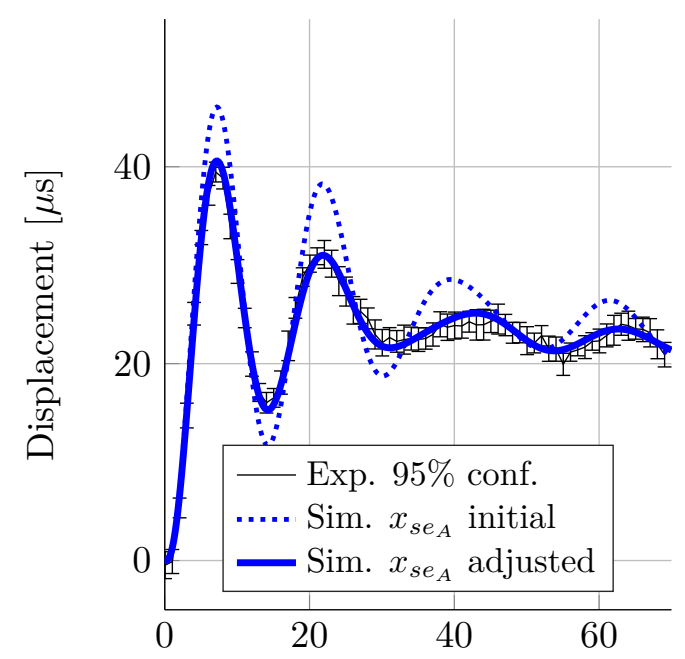

(a)

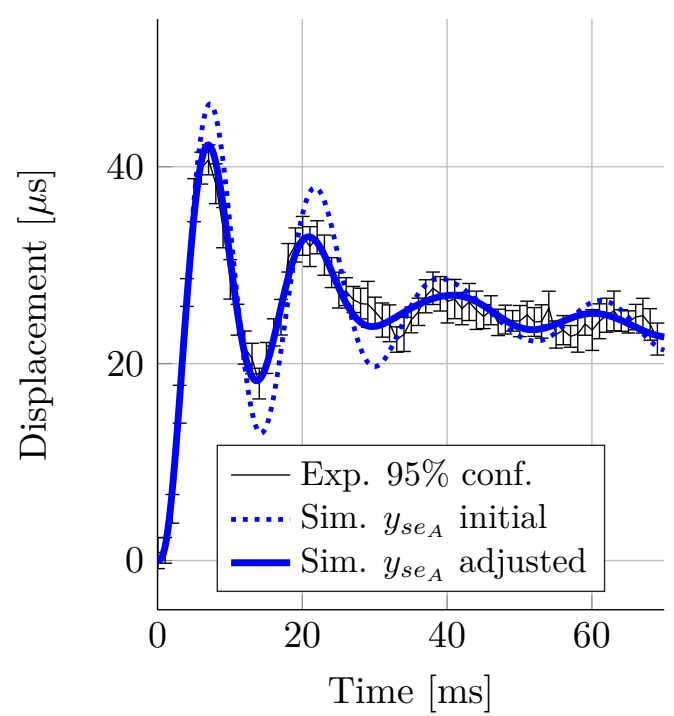

(b)

Figure 7: Rotor displacement at top sensors in response to a step in reference current of 0.03 A. The step is imposed in both bearings in the x-plane only. (a): x-direction. (b): y-direction.

120

of superimposing a step on the reference current on top of the reference control current. This effectively induces a force in the AMBs pulling the rotor laterally. The experiment has been repeated twenty times and the mean as well as the $95 \%$ confidence interval of the mean are plotted. The expected response has been simulated using the multiphysical model presented in [6]. The model parameters can be found in Appendix 


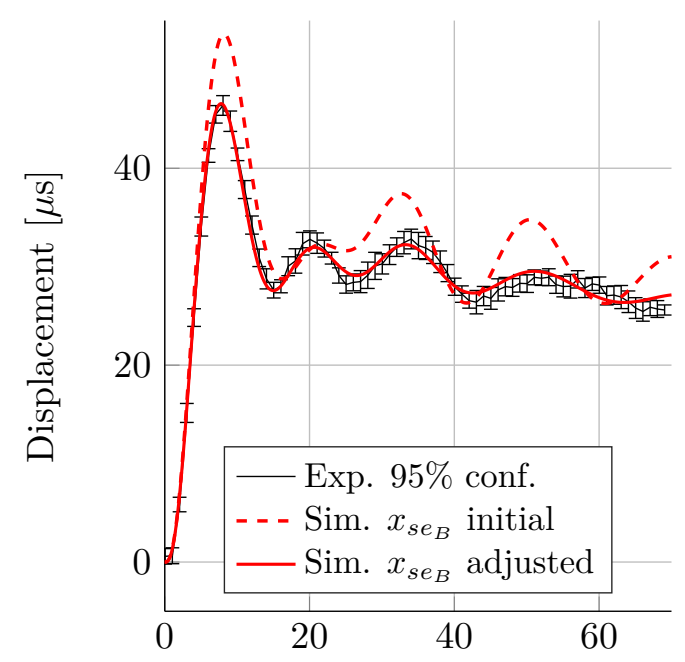

(a)

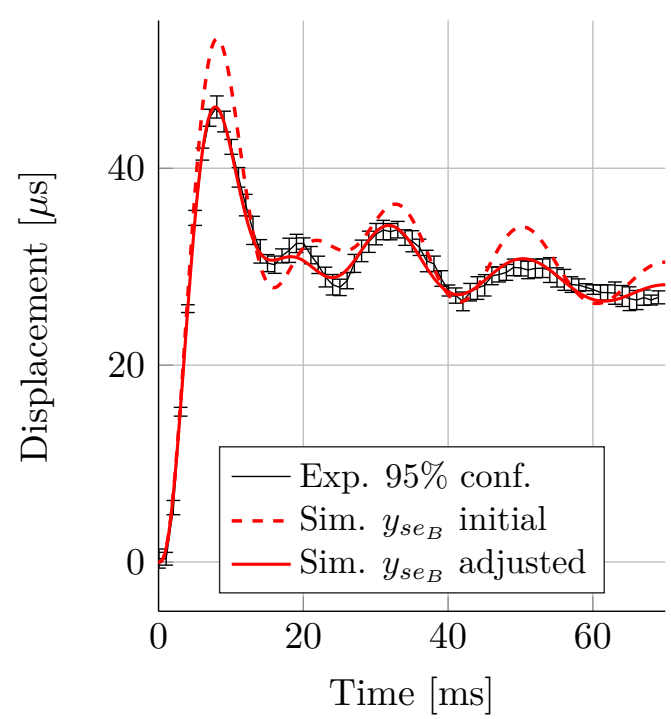

(b)

Figure 8: Rotor displacement at bottom sensors in response to a step in reference current of 0.03 A. The step is imposed in both bearings in the y-plane only. (a): x-direction. (b): y-direction.

$x_{0}$, the AMB cross-sectional area $A$, the rotor transversal mass moment of inertia $I_{r_{t}}$, the permanent magnet bearing stiffness $k_{r}$, and finally the motion induced voltage coefficient $k_{u}$ are subjected to some degree of uncertainty. Therefore, optimal values of these parameters are found by minimizing the sum of squares of the discrepancy of simulation and experimental data. The experimental data used, are the data from

Fig. 7 and 8 A detailed description of the parameter optimisation method can be found in [12. The values are allowed to deviate a maximum of $30 \%$ from the initial values. The deviation of $30 \%$ is well justified by the rough tolerances of the manufacturing process used for the AMBs. Furthermore, the presence of flux leakage, magnetic hysteresis, and especially eddy-currents are not accounted for in the model. All model parameters before and after optimization can be found in Appendix A.

The adjusted model with the optimal values of $x_{0}, A, I_{r_{t}}, k_{r}$, and $k_{u}$ is simulated and the results can be seen as solid thicker lines in the figures. The simulated rotor displacement at both top and bottom sensors resemble the experiments well. By updating the parameters, theoretical and experimental rotor responses fit well, leading to the conclusion that the structure of the model is correct and able to describe the system dynamic behaviour.

The maximum displacement at the top sensors is 44 and $46 \mu \mathrm{m}$ respectively. At the bottom sensors, the maximum displacement is 53 and $51 \mu \mathrm{m}$. The larger displacement at the bottom sensors is due to the negative radial stiffness of the permanent magnet bearing placed in the bottom.

In Fig. 9 and 10 the coil currents are compared. The experimental data for the currents have not been used to find the optimal values for the adjusted model. Still, we see that the currents follow the same trend as the displacement and that theory and experiments agree well when using the adjusted parameters. The 

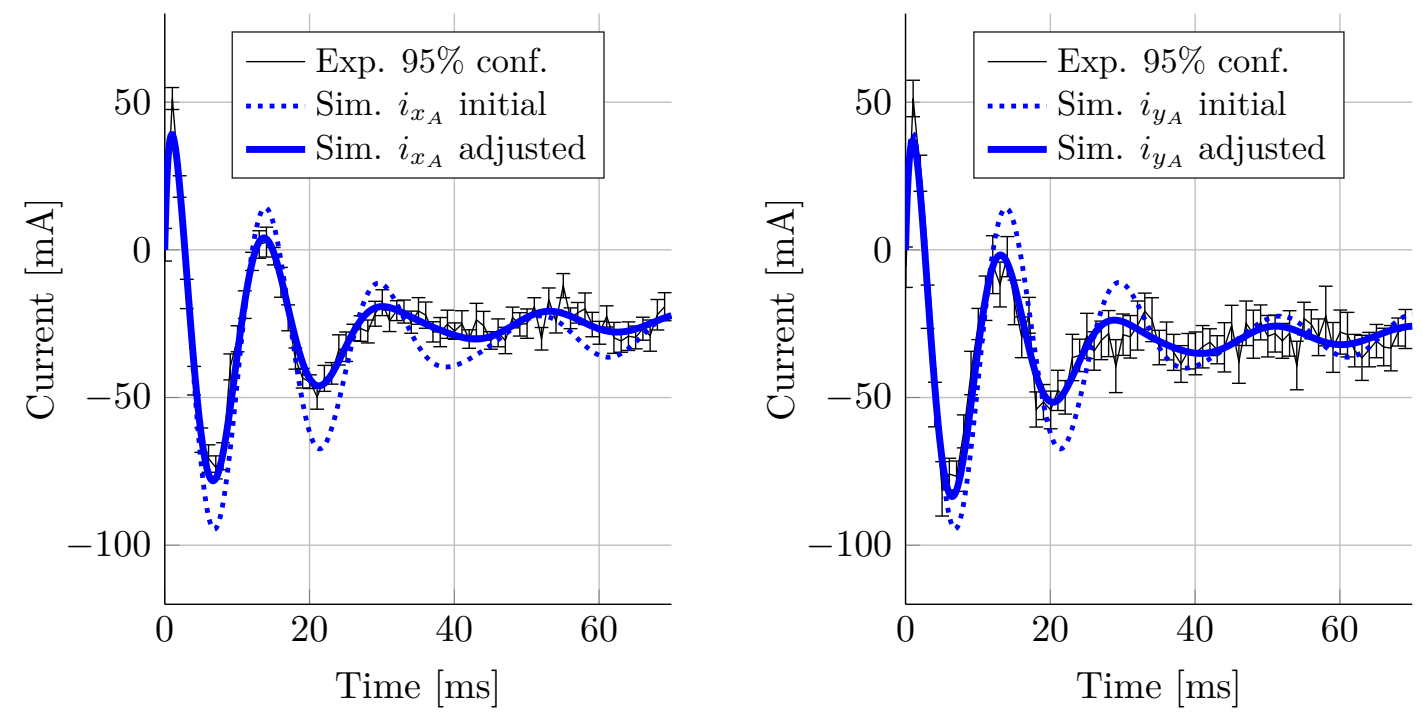

(a)

Figure 9: Control current in top AMB in response to a step in reference current of 0.03 A. (a): Coil for x-directional actuator. (b): Coil for y-directional actuator.
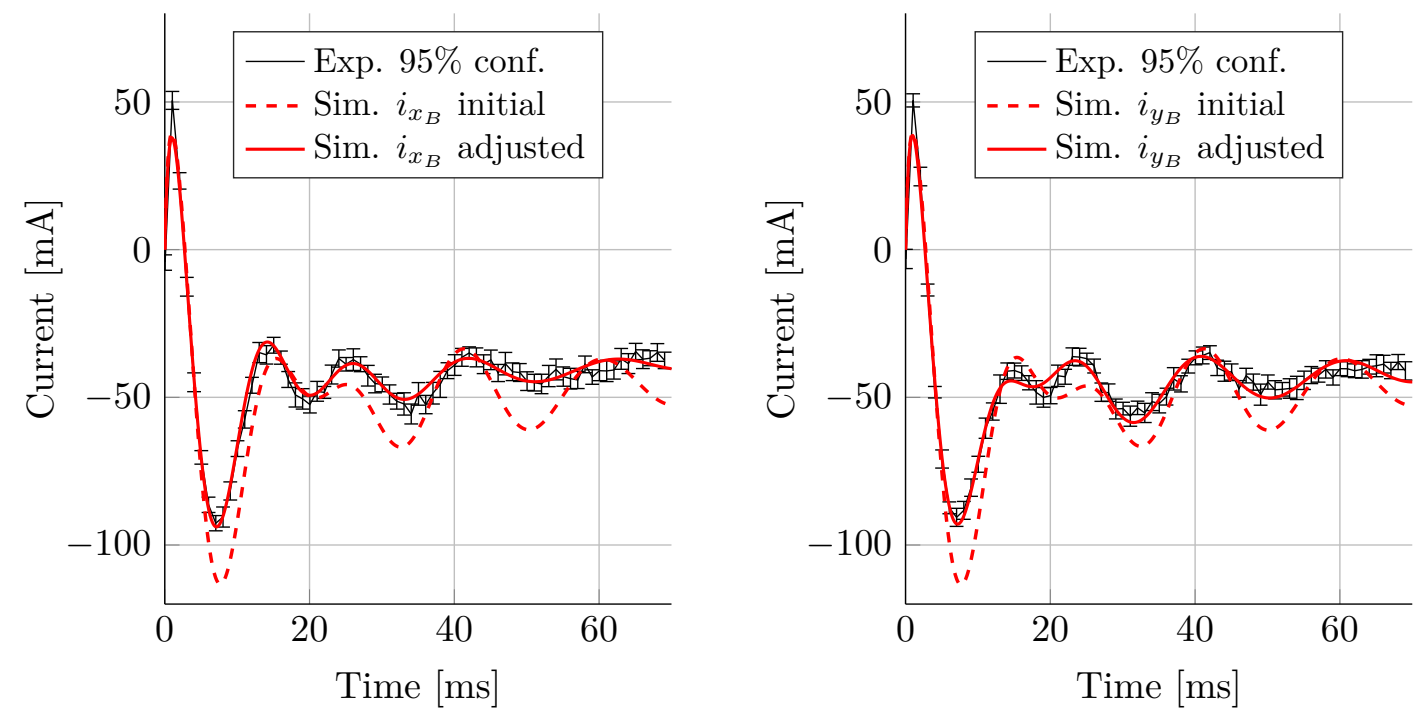

(a)

Figure 10: Control current in bottom AMB in response to a step in reference current of $0.03 \mathrm{~A}$. (a): Coil for x-directional actuator. (b): Coil for y-directional actuator.

fact that the model agrees, not only for the displacements used to fit the model but also for the currents, indicates a more general validity of the model.

Fig. 11 and 12 show the frequency response functions (FRFs) obtained by imposing a chirp signal with linearly increasing frequency to the reference current simultaneously in top and bottom bearing in the $x$ direction. [H!] The chirp signal sweeps from 0 to $220 \mathrm{~Hz}$ in $120 \mathrm{~s}$. As seen, both amplitude and phase agrees. The amplitude of the chirp signal is $0.3 \mathrm{~A}$ in Fig. $11 \mathrm{k}$ and $12 \mathrm{k}$. The experiments are also done 

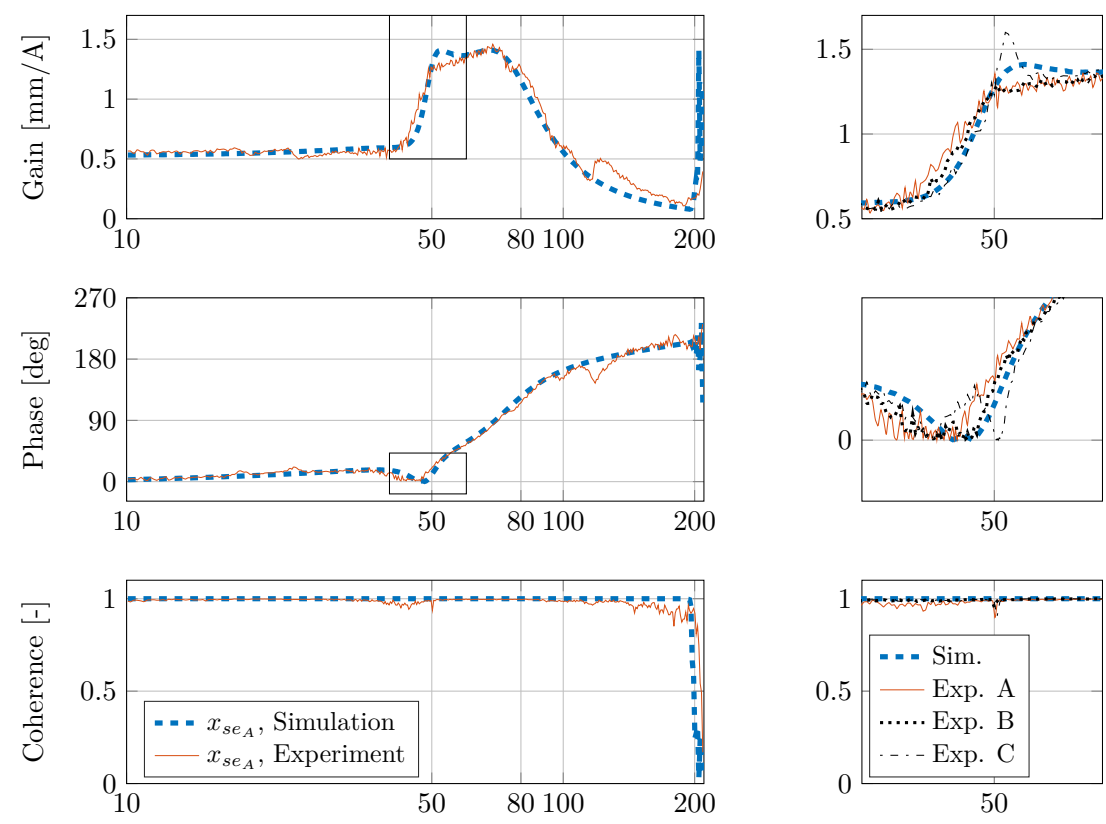

(a)

Freq. $[\mathrm{Hz}]$

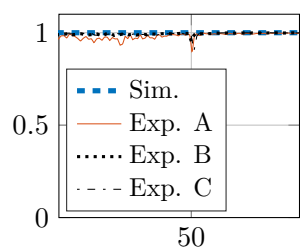

Freq. $[\mathrm{Hz}]$ (b)

Figure 11: (a): Frequency response obtained at top sensors (input: $i_{\mathrm{ref}_{x_{A}}}$, output: $x_{\mathrm{se}_{A}}$ ). (b): Zoom in. Experiments A, $\mathrm{B}$, and $\mathrm{C}$ figure (b) are obtained with a chirp input signal amplitude of $0.03 \mathrm{~A}, 0.06 \mathrm{~A}$, and $0.09 \mathrm{~A}$. The resulting maximum output displacements are $49 \mu \mathrm{m}, 96 \mu \mathrm{m}$, and $152 \mu \mathrm{m}$ respectively.

with other amplitudes to see if the experimentally obtained FRF will be deviating from the model for increasing amplitude and thus increasing the significance of non-linearities. It was found that the FRF started to deviate when the maximum rotor displacement became around $100 \mu \mathrm{m}$. This is illustrated in Fig. $11 \mathrm{p}$ and $12 \mathrm{~b}$ which zoom in on specific parts of the FRFs where the deviations can be seen. Experiment A and B have maximum displacements below $100 \mu \mathrm{m}$ and follow the theoretically obtained FRF nicely. Experiment $\mathrm{C}$ has maximum displacement above $100 \mu \mathrm{m}$ and is deviating from the theoretically obtained FRF.

\subsection{Housing Dynamics and Dissipative Forces}

Fig. 13 show the acceleration measured by the accelerometer when the housing is freely swinging. In the first experiment, Fig. $13 \mathrm{k}$, the housing is initially displaced with an angle $\alpha_{0}=25.4^{\circ}$. In the second experiment, Fig. $13 \mathrm{~b}$, the housing is initially displaced with an angle $\beta_{0}=24.0^{\circ}$. The accelerometer measures the absolute acceleration including gravity, and therefore the initial measured acceleration can be used to find $\alpha_{0}$ and $\beta_{0}$. The initial simulations are without any friction. The updated model has slightly adjusted transversal mass moment of inertia of housing and gimbal (the initial values were estimated from computeraided drawing (CAD) software). Furthermore, it contains a friction model for the torque acting between 

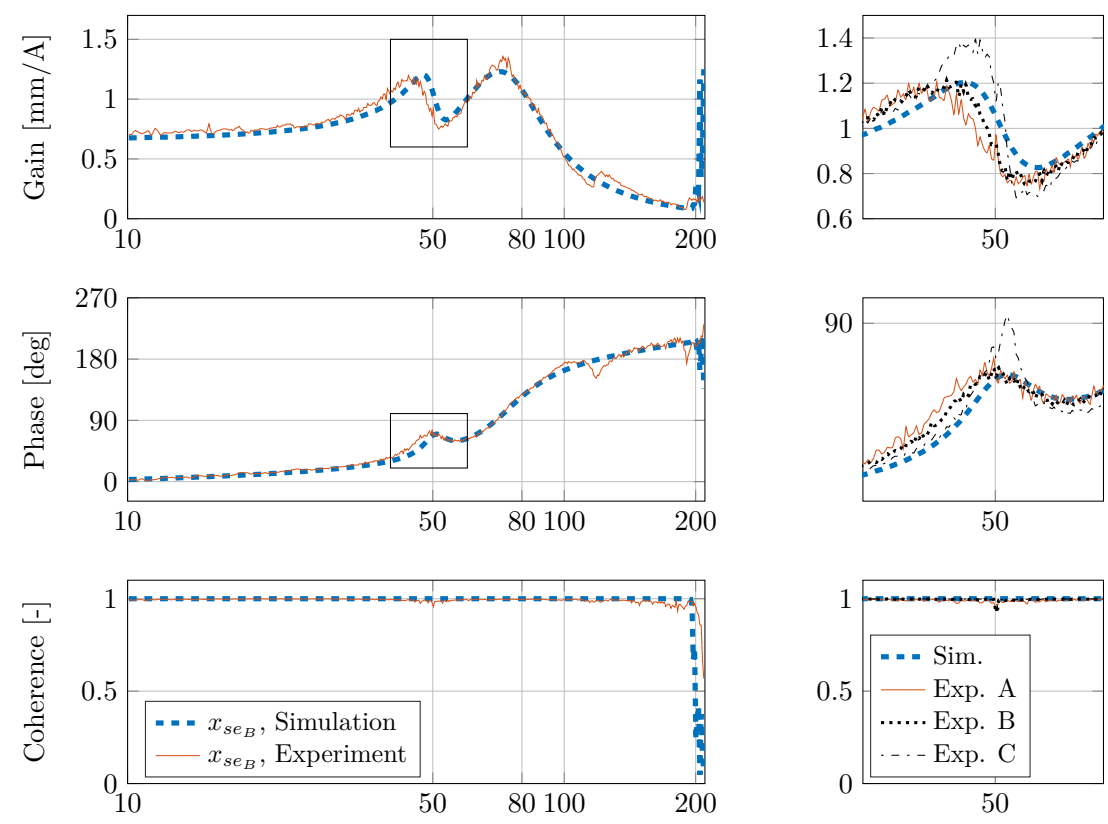

(a)

Freq. $[\mathrm{Hz}]$

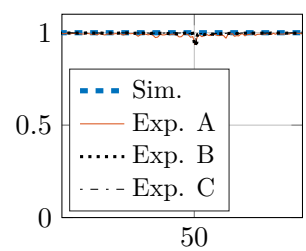

Freq. $[\mathrm{Hz}]$ (b)

Figure 12: (a): Frequency response obtained at bottom sensors (input: $i_{\text {ref }_{x_{B}}}$, output: $x_{\mathrm{se}_{B}}$ ). (b): Zoom in. Experiments A, $\mathrm{B}$, and $\mathrm{C}$ on figure (b) are obtained with a chirp input signal amplitude of $0.03 \mathrm{~A}, 0.06 \mathrm{~A}$, and $0.09 \mathrm{~A}$. The resulting maximum output displacements are $44 \mu \mathrm{m}, 96 \mu \mathrm{m}$, and $142 \mu \mathrm{m}$ respectively.

the tilting frame and gimbal $\tau_{y_{1}}$ and between the housing and gimbal $\tau_{x_{3}}$ :

$$
\begin{aligned}
& \tau_{y_{1}}=-\mu_{y_{1}} \dot{\alpha}-\nu_{y_{1}}\left(|\alpha|^{p_{y_{1}}} \operatorname{sign}(\dot{\alpha})|\dot{\alpha}|^{0.2}-\operatorname{sign}(\alpha)|\dot{\alpha}|^{0.2}\right) \\
& \tau_{x_{3}}=\mu_{x_{3}} \dot{\beta}+\nu_{x_{3}}\left(|\beta|^{p_{x_{3}}} \operatorname{sign}(\dot{\beta})|\dot{\beta}|^{0.2}-\operatorname{sign}(\beta)|\dot{\beta}|^{0.2}\right)
\end{aligned}
$$

Where the parameters $\mu_{y_{1}}, \nu_{y_{1}}, p_{y_{1}}, \mu_{x_{3}}, \nu_{x_{3}}, p_{x_{3}}$ are found empirically. The first term represents viscous damping. The second term is physically justified by the many wires and cables connected to the housing which are unavoidably adding significant damping. This damping is dependent on the amplitude of the swinging motion as large displacements will stretch the wires and cables adding additional stiffness. This is seen in Fig. 13, where the frequency is decreasing with decreasing amplitude. Therefore the second term is dependent on $\alpha$ and $\beta$. The term also includes the factors $|\dot{\alpha}|^{0.2}$ and $|\dot{\beta}|^{0.2}$. The only purpose of these factors is to smoothen the discontinuity that would otherwise occur in the second term when the velocities $\dot{\alpha}$ and $\dot{\beta}$ change sign. An illustration of the vectors $\tau_{y_{1}}$ and $\tau_{x_{3}}$ is found in the free-body diagram of the gimbal in [6].

As seen from Fig. 13, the updated model is capturing the simple swinging motions well.

In Fig. 14 the housing is manually displaced with an initial angle $\alpha_{0}=23.4^{\circ}$. Additionally, the rotor is spinning at $15 \mathrm{kRPM}$. Thus, when the housing is released and starts to move, it will do precession and nutation movements with a high frequency $\omega_{2}$ and a low frequency $\omega_{1}$ respectively. As seen from 

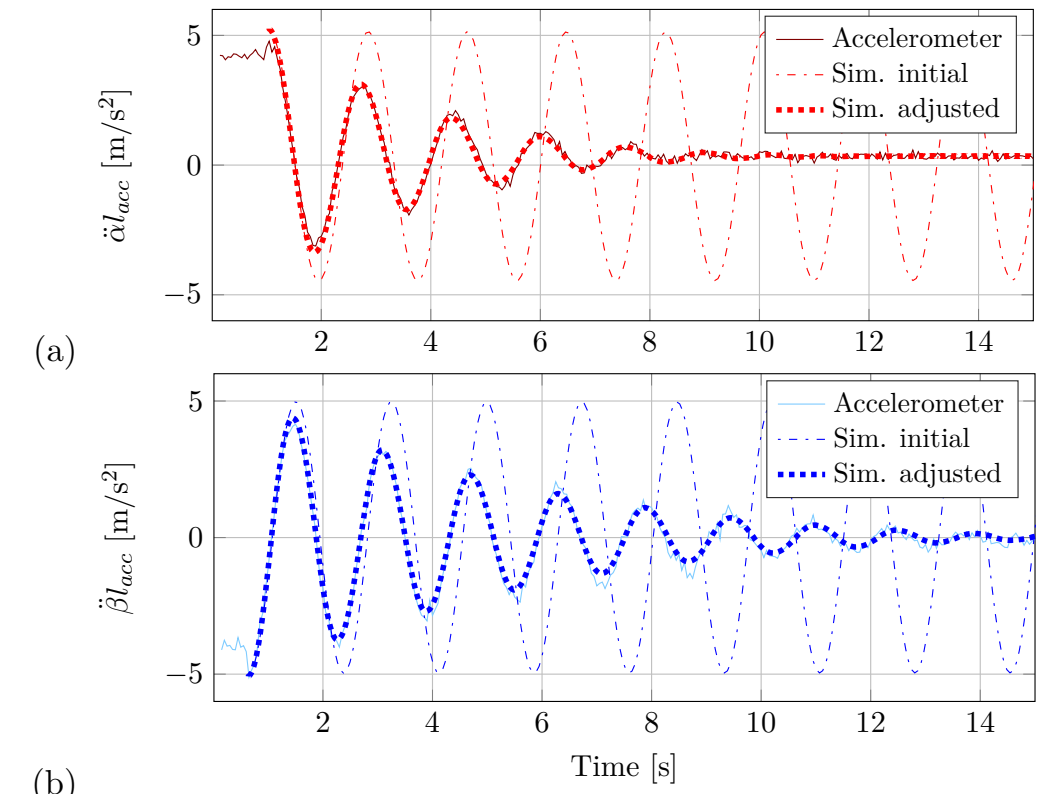

(b)

Figure 13: Acceleration at the location of the accelerometer after an initial angular displacement of (a): $\alpha_{0}=25.4^{\circ}$, and (b): $\beta_{0}=24.0^{\circ}$.

(a)
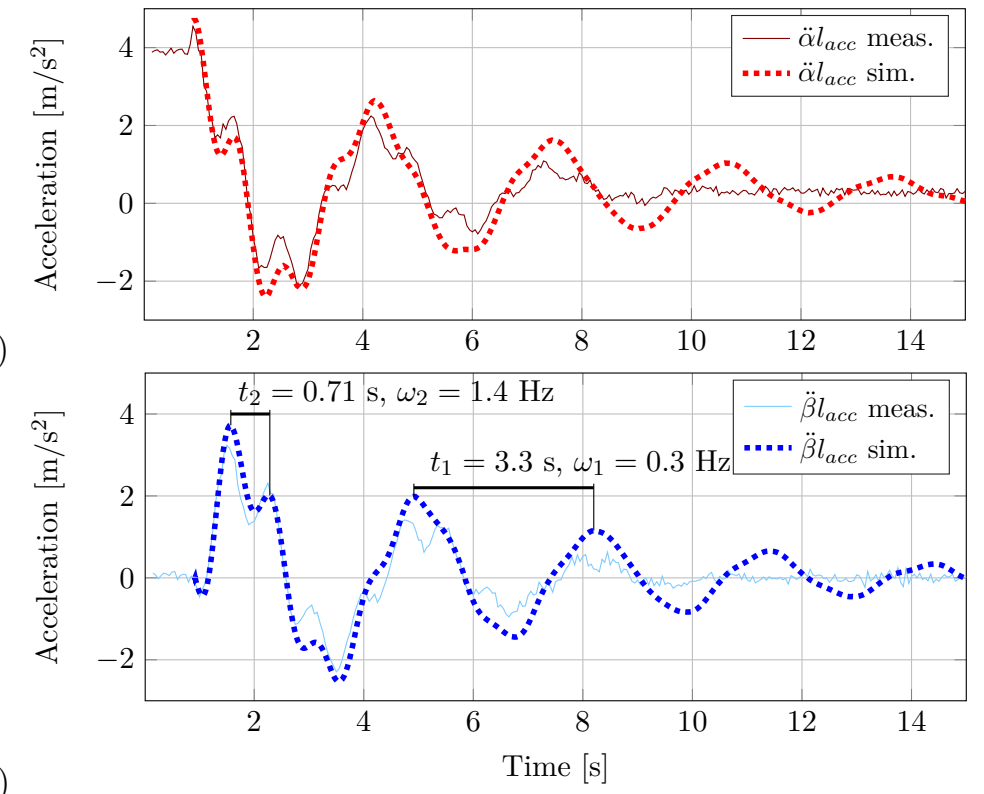

(b)

Figure 14: Accelerations at the location of the accelerometer when the housing is initially displaced with $\alpha_{0}=23.4^{\circ}$ and the rotor is rotating with $15 \mathrm{kRPM}$. Due to gyroscopic force, movements in the two directions are coupled. A high frequency $\omega_{2}$ with period $t_{2}$ and a low frequency $\omega_{1}$ with period $t_{1}$ are present in the response.

Fig. 14, the model captures the high and low frequencies well. However, the damping is not agreeing well. The high frequency seems to be too highly damped in the model while the low frequency is not damped 
enough. Therefore, one could argue for the need of an improved friction model to better capture the exact vibration amplitudes. However due to the following, it has been decided to keep the model as it is: 1) The vibration levels are approximately the same for simulation and experiment, 2) the current friction model is conservative and predicts larger vibrations than the actual vibrations, 3) the frequencies agree, and finally 4) the friction which mainly comes from the cables and wires are specific for the current test rig and in a real application, the cables and wires will probably be connected differently and thus another friction model would be required.

\subsection{Dynamics when Foundation is Moving.}

All presented accelerations of the foundation are obtained by measuring the position of the pneumatic actuator cylinders and then numerically differentiating the data. Smoothening and filtering have been used to reduce noise in the final outcome. The obtained vehicle acceleration has then been used as an input to the numerical model.

First, we will look at the movements of the rotor when the housing is latched to the foundation corresponding to a non-gimballed system.

\section{No Gimbal (Latched Housing)}

Fig. 15 shows the displacements of the rotor relative to the housing when vehicle and housing are surging forward. The acceleration of the vehicle is shown together with the resulting rotor displacement. The simulated rotor position is seen to resemble the measured rotor position well.

In Fig. 16, the rotor is rotating at $9600 \mathrm{RPM}$ and the vehicle is rolling with roll angle $\phi$ as seen in Fig. 16 p. As soon as the vehicle starts to roll, the rotor starts to move relative to the housing due to the gyroscopic effects. The rotor is rotating around the axis perpendicular to the roll axis as expected. Again, the simulated responses resemble the measurements well. It should be mentioned that the high frequency vibrations on top of the low frequency oscillations are due to rotor unbalance and has a frequency which is synchronous with the rotational speed (1X).

\section{With Gimbal}

In Fig. 17, the dynamics of the housing are investigated when the vehicle is surging and the housing is free to rotate in the gimbal. The rotor is rotating at 30500 RPM. In Fig. $17 \mathrm{~d}$ we see the measured acceleration of the frame which is used as an input for the mathematical model. The gray area spans the time in which the vehicle is accelerating forward (surging). The red area spans the time where the vehicle experiences an abrupt stop. In Fig. 17 and 17 p, the housing accelerations measured by the accelerometer 18 are compared with theoretical results. The vehicle acceleration makes the housing swing like a pendulum. It is seen how the high rotational speed results in significant gyroscopic effects effectively making the housing do precession motions. This can be seen in the figure as the housing pendulum motions are in both the $x$ and $y$-direction 


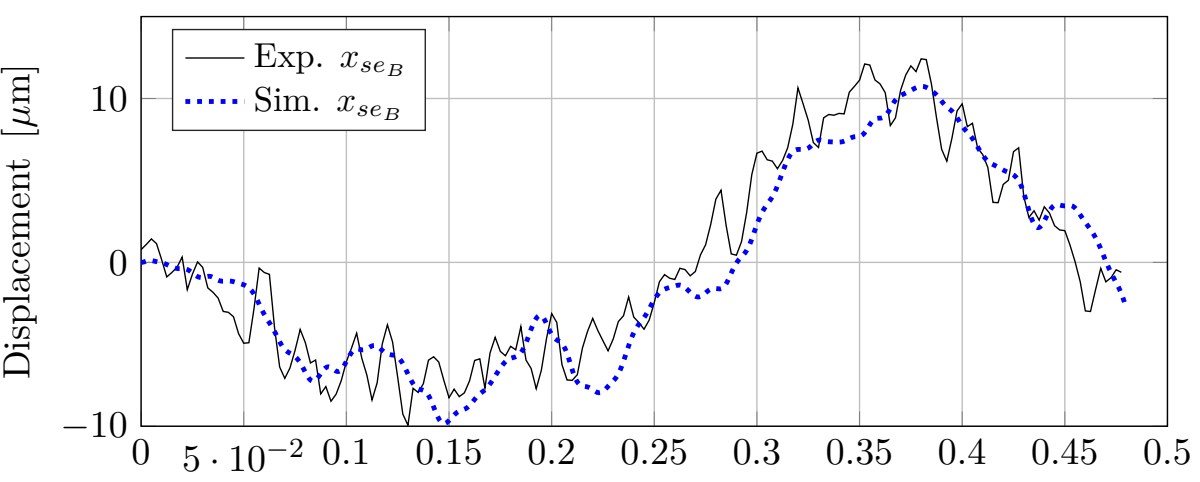

(a)

(b)

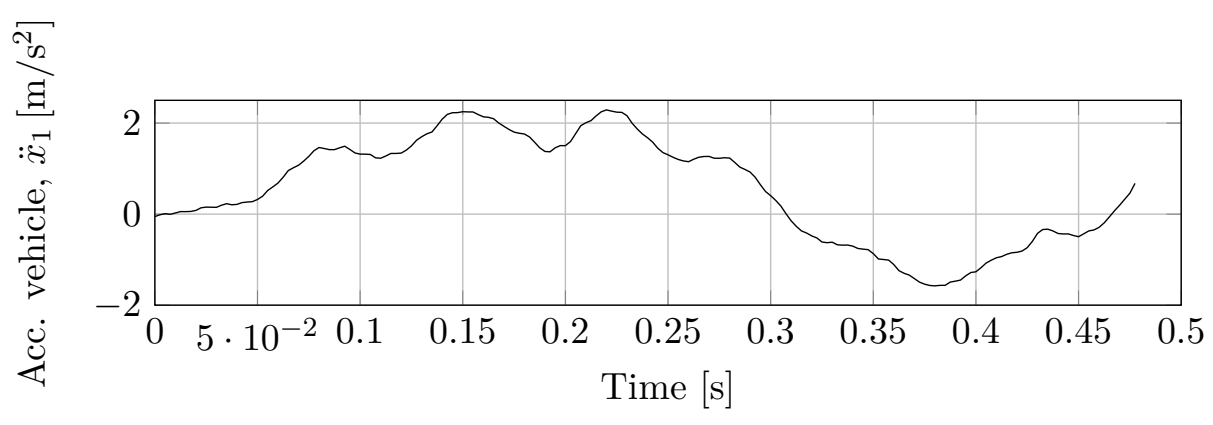

Figure 15: (a) The displacement of the non-rotating rotor due to (b) a surging vehicle. No gimbal is present.

(circular motion). The model captures the dynamics of the housing well in all three phases - surging, impact, and free response. The largest acceleration is naturally found in the period of impact in the surge-direction. to friction in the gimbal joints, the rolling vehicle causes the housing to also roll slightly and consequently do a precession motion. This causes the rotor to move relative to the housing as seen in Fig. 18 . The experimental and numerical results agree well. When comparing the results with the results of Fig. 16a (rolling vehicle but no gimbal), we see that the rotor dynamics are of the same magnitudes although the rotational speed is more than twice the rotational speed of the rolling vehicle experiment without gimbal.

The magnitude reaches $13.5 \mathrm{~m} / \mathrm{s}^{2}$ in the simulated case and $13.7 \mathrm{~m} / \mathrm{s}^{2}$ in the experimental case resulting in a deviation of $2 \%$. In Fig. 17 , the measured and simulated rotor displacements at the bottom sensor are shown. When the impact is occurring, the measured maximum displacement amplitude is $127.2 \mu \mathrm{m}$ while the simulated displacement amplitude is only 80.2 leading to a deviation of $37 \%$. This deviation may be caused by non-linearities of the magnetic bearings starting to significantly affect the dynamics at these large displacements. For the smaller rotor displacements in the surging phase and the free response phase, the model agrees well with the experiments. In conclusion, fig. 17 shows how the dynamics of both housing and rotor are captured well when an outer perturbation is imposed on the system. This means that the model is successfully capturing the dynamics all the way from the input vehicle movements, through the gimbal, the housing, the magnetic bearings, and to the rotor.

Last, we will look at the response of the rotor when the vehicle is rolling and the housing is gimballed. Due 


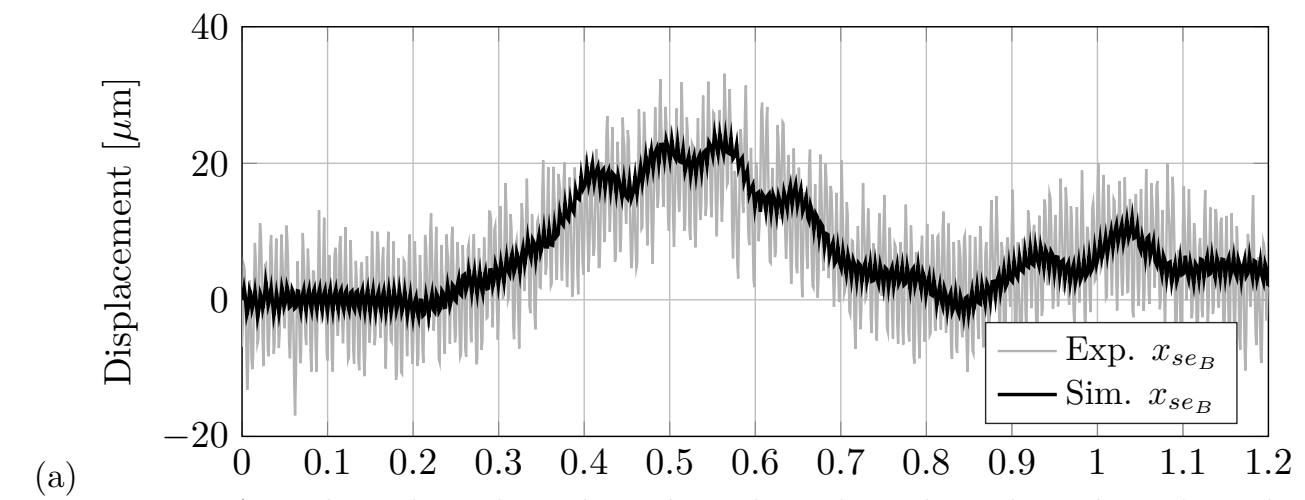

(b)
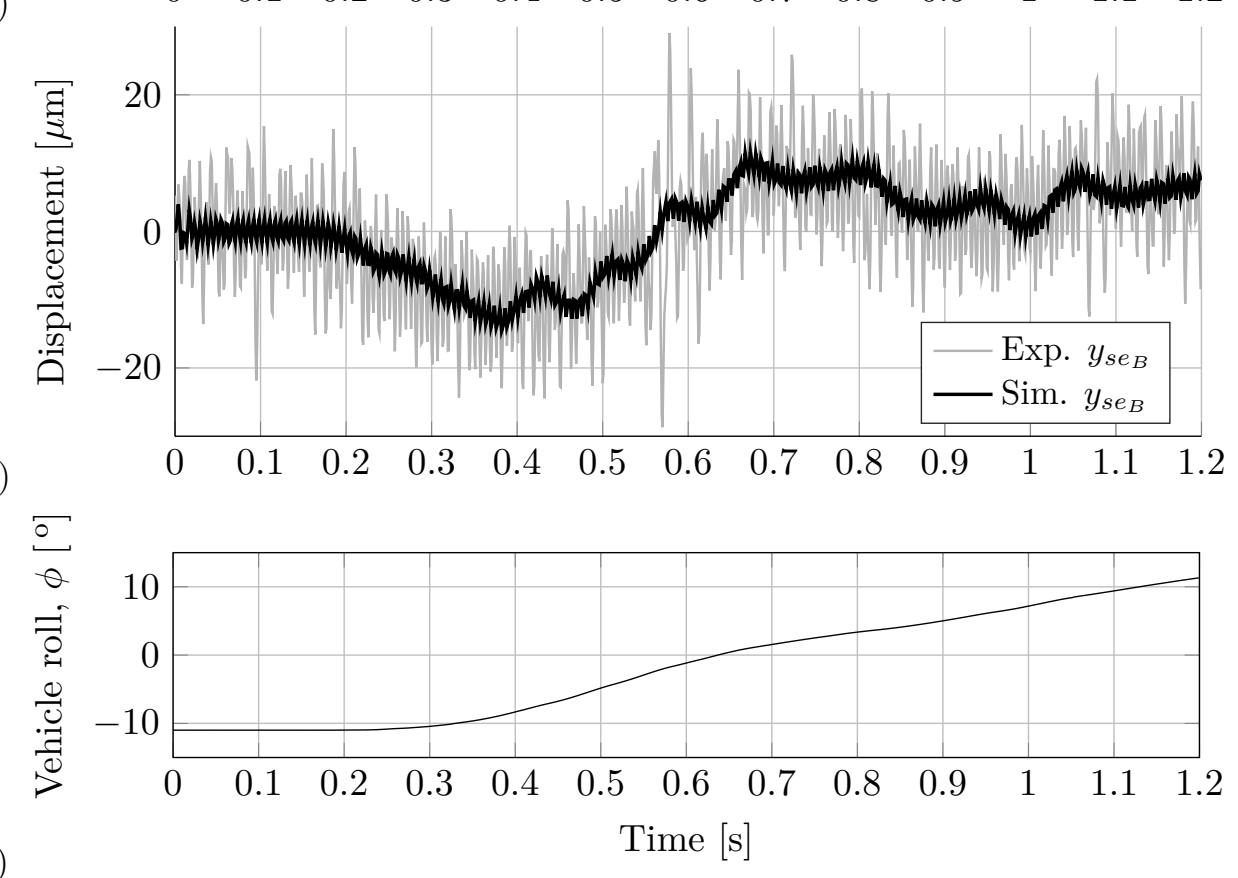

Figure 16: (c) Rolling vehicle and the resulting displacements of the rotor in (a) $x$-direction and (b) $y$-direction. Rotational speed of rotor is 9600 RPM. No gimbal is present.

This indicates how the gimbal mount allows for larger rotational speeds when the vehicle is rolling and thus the gyroscopic forces would have dominated if the gimbal was not present. 


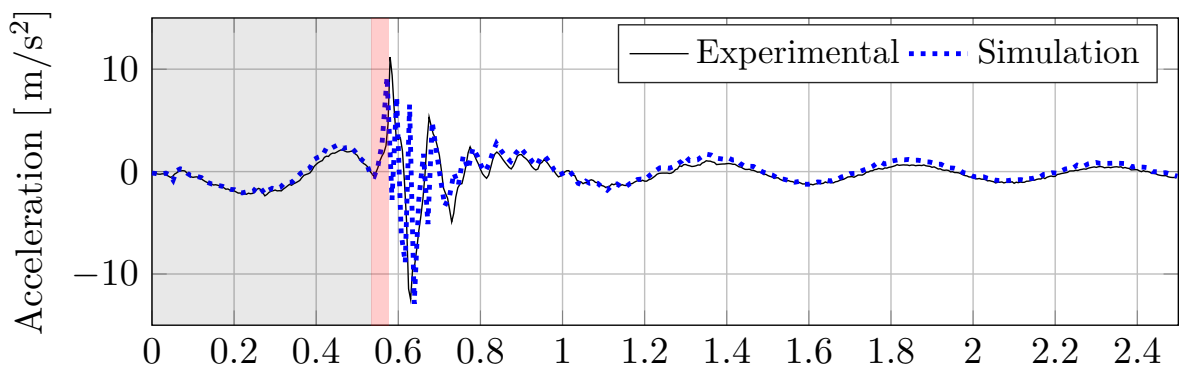

(a)

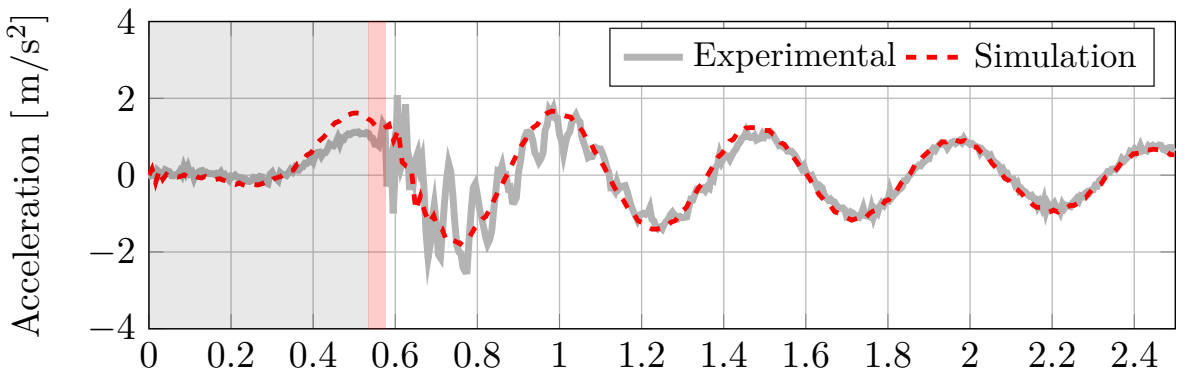

(b)

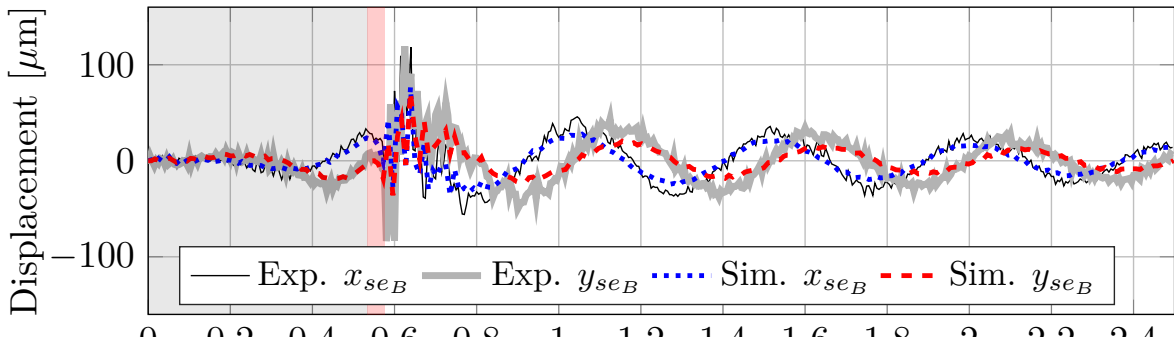

(c)

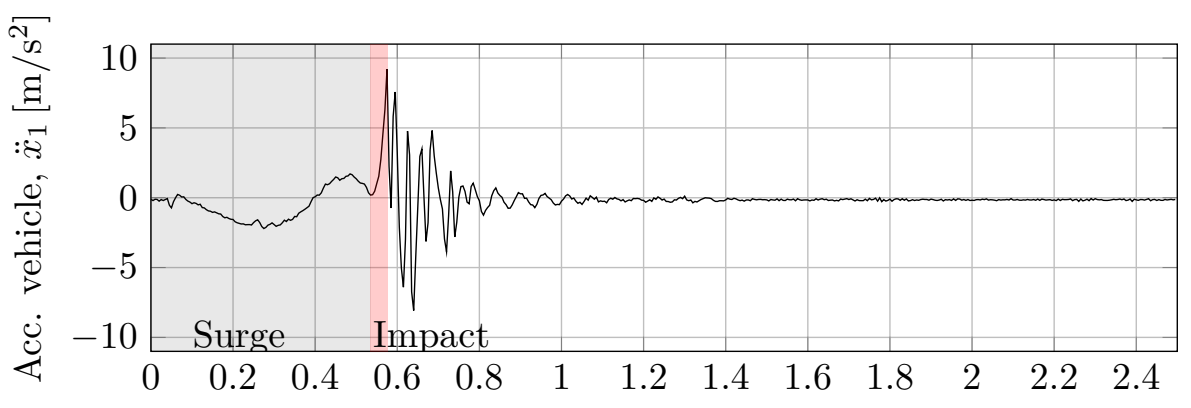

(d)

Time $[\mathrm{s}]$

Figure 17: Surging vehicle and rotor with rotational speed of 30500 RPM. The accelerations measured on top of the gimballed housing are compared to numerical results. Note that measured and simulated housing accelerations include the absolute acceleration which increases as the housing tilts. (a): Acceleration of housing, $x$-direction. (b): Acceleration of housing, $y$-direction. (c): Rotor movements. (d): Acceleration of Vehicle. 
(a)
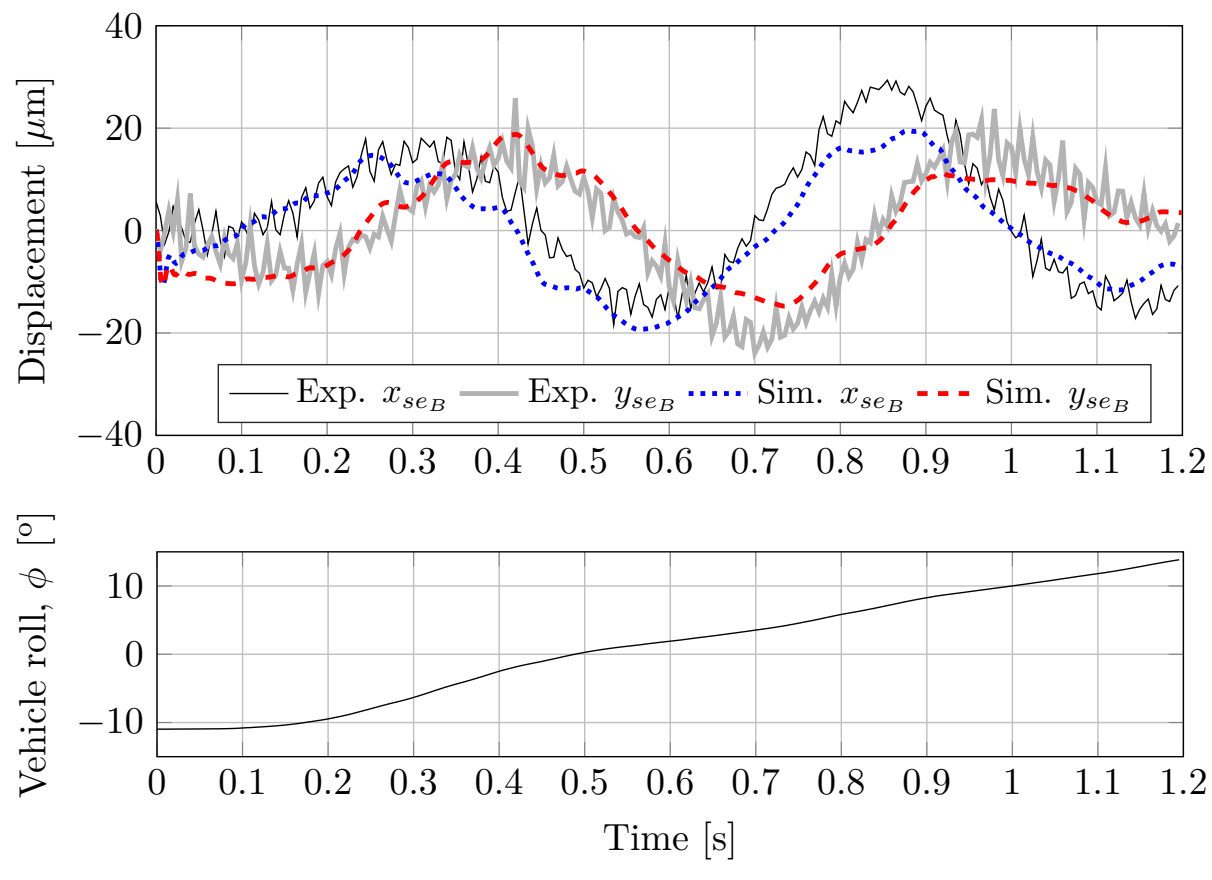

Figure 18: Rolling vehicle and rotor with rotational speed of 20340 RPM. The housing is gimballed but due to friction in joints, the vehicle roll makes the rotor move.

\section{Conclusion}

An experimental test set-up of a gimbal-mounted magnetically suspended rotor on a moving foundation was presented. All hardware and software components were described in detail. The test rig is modular and can easily be reconfigured to test other types of magnetic bearings, backup bearings, sensors, or motor/generators. The outcomes of numerous experimental tests were presented and compared with simulations carried out using the model presented in [6]. The tests were categorized based on the three sub-systems that they each shed light upon:

- Stationary housing and foundation: Letting only the rotor move, it is investigated how the rotor and magnetic bearings are behaving when subject to a step input and chirp inputs of varying amplitude. It is found that the model predicts the rotor displacements and AMB coil dynamics well up to a maximum rotor displacement of around $100 \mu \mathrm{m}$. For rotor displacements larger than this, the non-linearities of the magnetic forces are significant and can no longer be neglected.

- Gimballed housing: Letting the housing swing freely, it was found that the housing movements can be captured by the model if a fairly simple friction model is used. The friction model is dependent on the housing angular velocities but also displacements. The gyroscopic effects that occur when the rotor is rotating and the housing is swinging are also demonstrated and compared with theoretical 
results with good agreement.

- Moving foundation: The whole system is perturbed by having the foundation surge and roll. It is demonstrated how the gyroscopic forces cause the rotor to move when the foundation is rolling and no gimbal is present. When the gimbal is present, it is demonstrated how the rotational speed can be increased compared to the non-gimballed case without any significant enlargement of rotor movements. In the gimballed case, rotor movements are still present when the foundation is rolling due to friction in the gimbal joints.

Tests where the frame is surging and the rotor is running at $30500 \mathrm{RPM}$ are also carried out. It is found that the housing movements are captured well both when the frame is surging, when it is abruptly stopping (impact), and afterwards during free vibrations. The maximum housing accelerations are measured during impact and are only $2 \%$ different from the simulation results. The rotor displacements are also captured well during surging and during the free response. However, the displacements are underestimated by the model during impact by $37 \%$ due to the large displacements (above $100 \mu \mathrm{m}$ ) which make the magnetic bearings behave non-linearly.

It can be concluded that the model is successfully capturing the dominating dynamics of the test rig as long as the rotor displacements are kept below $100 \mu \mathrm{m}$ (50\% of the backup bearing clearance). Thus, the multi-physical model governing motions of gimbal, housing, and rotor on a moving foundation has been successfully validated against experimental results. The model successfully takes into account passive and active magnetic forces including control algorithm dynamics and AMB coil dynamics.

\section{Acknowledgements}

The authors gratefully acknowledge the support from the Innovation Fund Denmark Grant and the input from Maersk Drilling and WattsUp Power. 


\section{Appendix A. Input Parameters}

\begin{tabular}{|c|c|c|c|c|c|}
\hline & Unit & $\begin{array}{c}\text { Fig. } 7-12 \\
\text { initial }\end{array}$ & $\begin{array}{c}\text { Fig. } 7-12 \\
\text { adjusted }\end{array}$ & $\begin{array}{c}\text { Fig. } 13-18 \\
\text { initial }\end{array}$ & $\begin{array}{c}\text { Fig. } 13-18 \\
\text { adjusted }\end{array}$ \\
\hline$\theta(t)$ & {$[\mathrm{rad}]$} & 0 & 0 & 0 & 0 \\
\hline$\ddot{x}_{1}$ & $\mathrm{~m} / \mathrm{s}^{2}$ & 0 & 0 & 0 & 0 \\
\hline$z_{0}$ & $\mathrm{~m}$ & 0.0109 & 0.0109 & 0.0109 & 0.0109 \\
\hline$z_{3-4}$ & {$[\mathrm{~m}]$} & 0.413 & 0.413 & 0.413 & 0.413 \\
\hline$l$ & {$[\mathrm{~m}]$} & 0.0177 & 0.0177 & 0.0177 & 0.0177 \\
\hline$l_{\mathrm{acc}}$ & {$[\mathrm{m}]$} & 0.1802 & 0.1802 & 0.1802 & 0.1802 \\
\hline$a$ & {$[\mathrm{~m}]$} & 0.0412 & 0.0412 & 0.0412 & 0.0412 \\
\hline$b$ & {$[\mathrm{~m}]$} & 0.0348 & 0.0348 & 0.0348 & 0.0348 \\
\hline$c$ & {$[\mathrm{~m}]$} & 0.0852 & 0.0852 & 0.0852 & 0.0852 \\
\hline$d$ & {$[\mathrm{~m}]$} & 0.0748 & 0.0748 & 0.0748 & 0.0748 \\
\hline$e$ & {$[\mathrm{~m}]$} & 0.1384 & 0.152 & 0.1384 & 0.1384 \\
\hline$G$ & {$[\mathrm{~m}]$} & 0.158 & 0.158 & 0.158 & 0.158 \\
\hline$h$ & {$[\mathrm{~m}]$} & 0.158 & 0.158 & 0.158 & 0.158 \\
\hline$\mu_{y_{1}}$ & {$\left[\mathrm{~m}^{2} \mathrm{~N} / \mathrm{s}\right]$} & - & - & 0 & 0.112 \\
\hline$\mu_{x_{3}}$ & {$\left[\mathrm{~m}^{2} \mathrm{~N} / \mathrm{s}\right]$} & - & - & 0 & 0.056 \\
\hline$\nu_{y_{1}}$ & [ ] & - & - & 0 & 0.042 \\
\hline$\nu_{x_{3}}$ & [ ] & - & - & 0 & 0.028 \\
\hline$p_{y_{1}}$ & {$[-]$} & - & - & 0 & 0.02 \\
\hline$p_{x_{3}}$ & {$[-]$} & - & - & 0 & 0.02 \\
\hline$m_{r}$ & {$[\mathrm{~kg}]$} & 3 & 3 & 3 & 3 \\
\hline$m_{h}$ & {$[\mathrm{~kg}]$} & 14.8 & 14.8 & 14.8 & 14.8 \\
\hline$m_{g}$ & {$[\mathrm{~kg}]$} & 1.634 & 1.634 & 1.634 & 1.634 \\
\hline$I_{r_{p}}$ & {$\left[\mathrm{~m}^{2} \mathrm{~g}\right]$} & 0.75 & 0.75 & 0.75 & 0.75 \\
\hline$I_{h_{p}}$ & {$\left[\mathrm{~m}^{2} \mathrm{~g}\right]$} & 46 & 46 & 46 & 46 \\
\hline$I_{g_{p}}$ & {$\left[\mathrm{~m}^{2} \mathrm{~g}\right]$} & 34 & 34 & 34 & 34 \\
\hline$I_{r_{t}}$ & {$\left[\mathrm{~m}^{2} \mathrm{~g}\right]$} & 22 & 24.5 & 24.5 & 24.5 \\
\hline$I_{h_{t}}$ & {$\left[\mathrm{~m}^{2} \mathrm{~kg}\right]$} & 185 & 185 & 185 & 167 \\
\hline$I_{g_{t}}$ & {$\left[\mathrm{~m}^{2} \mathrm{~kg}\right]$} & 17 & 17 & 17 & 15.7 \\
\hline$\tau_{m / g}$ & {$[\mathrm{~N} / \mathrm{m}]$} & 0 & 0 & 0 & 0 \\
\hline$u$ & {$[\mathrm{~g} \cdot \mathrm{mm}]$} & 0 & 0 & 0 & 0 \\
\hline$l_{u}$ & $\mathrm{~m}$ & 0 & 0 & 0 & 0 \\
\hline$g$ & {$\left[\mathrm{~m} / \mathrm{s}^{2}\right]$} & 9.82 & 9.82 & 9.82 & 9.82 \\
\hline$M$ & {$[\mathrm{kA} / \mathrm{m}]$} & 955 & 955 & 955 & 955 \\
\hline$w$ & {$[\mathrm{~mm}]$} & 3 & 3 & 3 & 3 \\
\hline$n_{z}$ & {$[-]$} & 10 & 10 & 10 & 10 \\
\hline$n_{r}$ & {$[-]$} & 3 & 3 & 3 & 3 \\
\hline$r$ & {$[\mathrm{~mm}]$} & $21.3,24.3,27.3$ & $21.3,24.3,27.3$ & $21.3,24.3,27.3$ & $21.3,24.3,27.3$ \\
\hline$k_{r}$ & {$[\mathrm{kN} / \mathrm{m}]$} & -20 & -17 & -17 & -17 \\
\hline$k_{z}$ & {$[\mathrm{kN} / \mathrm{m}]$} & 40 & 40 & 40 & 40 \\
\hline
\end{tabular}




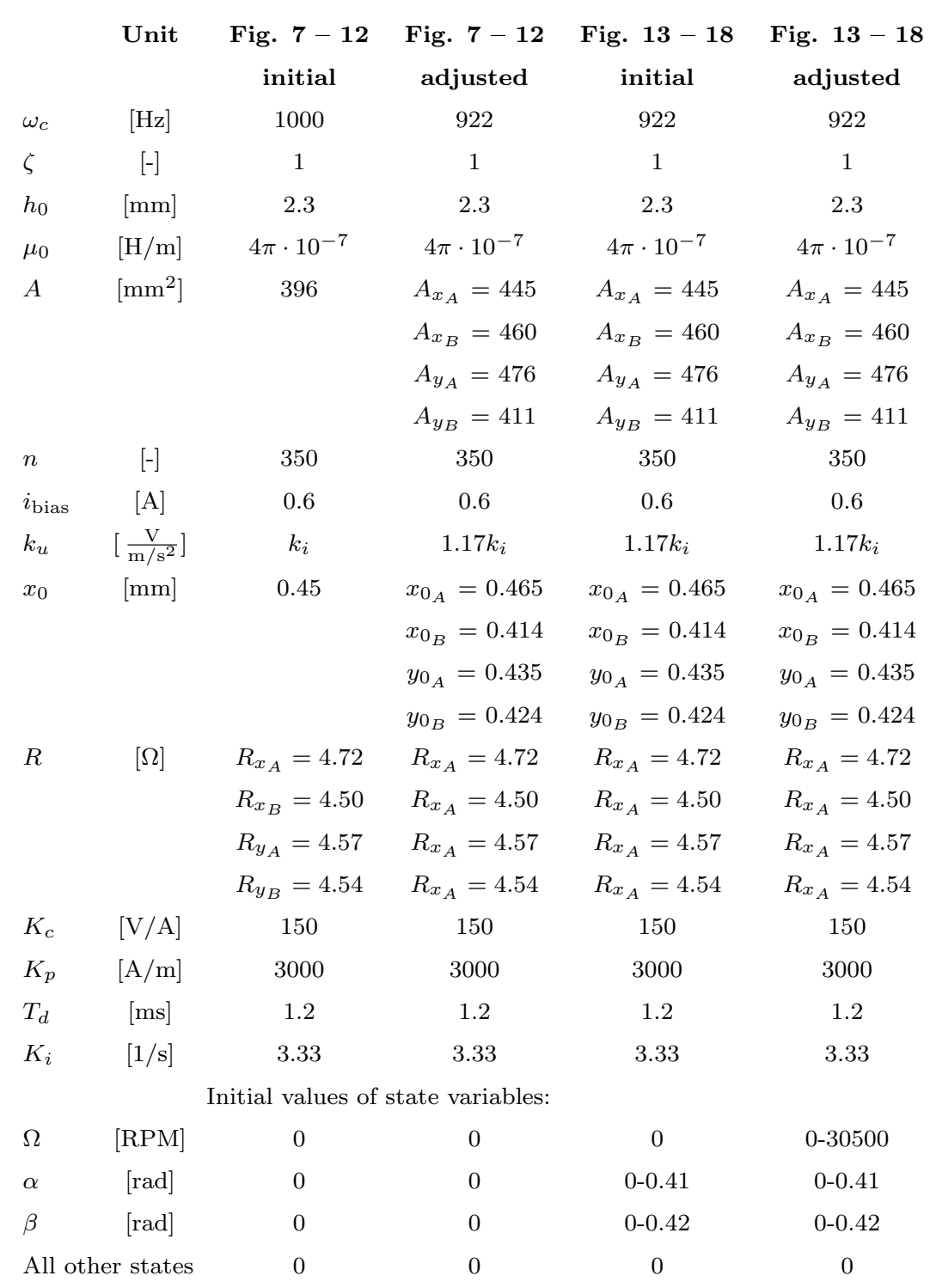

\section{References}

[1] B. Murphy, D. A. Bresie, J. H. Beno, Bearing Loads in a Vehicular Flywheel Battery, SAE Special Publications, Electric and Hybrid Vehicle Design Studies, Proceedings of the 1997 International Congress and Expositior doi:10.4271/970213

[2] L. Hawkins, B. Murphy, R. Hayes, J. Zierer, Shock and vibration testing of an AMB supported energy storage flywheel, JSME International Journal 46 (2) (2003) 429-435.

[3] M. M. Flynn, J. J. Zierer, R. C. Thompson, Performance testing of a vehicular flywheel energy system, SAE Technical Papers (2005) 1-10 doi:10.4271/2005-01-0809

[4] B. Rachmanto, K. Nonami, K. Kuriyama, H. Shimazaki, T. Kagamiishi, T. Moriya, A study on amb flywheel powered electric vehicle, Journal of System Design and Dynamics 3 (4) (2009) 659-670. doi:10.1299/jsdd.3.659

[5] F. Shimizu, K. Nonami, Benchmark and Verification of Control Algorithm for Flywheel with Active Magnetic Bearing on 
Electric Vehicle and Proposal of New SAC Algorithm ( $\epsilon 1$ modification and bias variable $\Gamma$ p approach ), ISMB14 (2014) $313-318$.

[6] N. A. Dagnæs-Hansen, I. F. Santos, Magnetically suspended flywheel in gimbal mount - nonlinear modelling and simulation, Journal of Sound and Vibration 432 (2018) 327-350. doi:10.1016/j.jsv.2018.06.033.

[7] B. Knapp, D. Arneson, D. Martin, Electrical Runout Using an Eddy-Current Sensor for Roundness Measurements, Aspe.Net (2013) 5-9Available online: http://www.aspe.net/publications/ShortAbstracts13A/3877.pdf [Accessed Nov. 30th 2017].

[8] S. Lahriri, I. F. Santos, H. I. Weber, H. Hartmann, On the nonlinear dynamics of two types of backup bearings theoretical and experimental aspects, Journal of Engineering for Gas Turbines and Power 134 (11) (2012) 805-+. doi: $10.1115 / 1.4007166$

[9] C. A. L. L. Fonseca, I. F. Santos, H. I. Weber, Experimental comparison of the nonlinear dynamic behavior of a rigid rotor interacting with two types of different radial backup bearings: Ball and pinned, Tribology International 119 (2018) 250-261. doi:10.1016/j.triboint.2017.07.018

[10] R. Larsonneur, P. Bühler, New Radial Sensor for Active Magnetic Bearings, Ninth International Symposium on Magnetic Bearings.

[11] C. Power, Typical data for SURA M270-35A, cogent-power.comAvailable online: https://cogent-power.com/cms-data/ downloads/m270-35a_1.pdf [Accessed Nov. 30th 2017].

[12] J. Lauridsen, I. F. Santos, On-site Identification of Dynamic Annular Seal Forces in Turbo Machinery Using Active Magnetic Bearings - An Experimental Investigation, ASME. J. Eng. Gas Turbines Power (2017) 1-11Doi: 10.1115/1.4038755. 